\title{
Psychometric characteristics and measurement invariance across genders of the Multidimensional Scale of Perceived Social Support (MSPSS) among Nigerian adolescents
}

\section{BACKGROUND}

The Multidimensional Scale of Perceived Social Support (MSPSS) in terms of its factor structure, reliability, validity and measurement invariance across genders has not been examined among Nigerian adolescents.

\section{PARTICIPANTS AND PROCEDURE}

We evaluated the psychometric properties and gender invariance of the MSPSS among Nigerian senior high school adolescents $\left(N=1335, M_{\text {age }}=15.15\right)$. Other study measures completed were the Hospital Anxiety and Depression Scale (HADS), the Positive and Negative Suicide Ideation Inventory (PANSI), and the Rosenberg Self-Esteem Scale (RSES). The four models of the MSPSS described in the literature were compared with confirmatory factor analysis (CFA). The model with the best fit indices was examined for its internal consistency by calculating the MacDonald's omega $(\omega)$ while criterion validity was examined through correlational analyses with other study measures. Measurement invariance in relation to gender was assessed with multigroup nested CFA.
RESULTS

Our results confirmed the original 3-factor structure of the MSPSS (Family, Significant others, and Friends). CFA showed that our data equivalently fitted the first (original first order 3-factor) and the fourth (second order 3-factor) MSPSS models. The reliability and criterion validity were satisfactory. Configural, metric and scalar measurement invariances in relation to genders were confirmed.

\section{CONCLUSIONS}

The 3-factor MSPSS either in its original (first-order) or second-order model is useful as a perceived social support assessment instrument among Nigerian adolescents.

\section{KEY WORDS}

perceived social support; psychometric properties; gender invariance; Nigerian adolescents

Organization - 1: Obafemi Awolowo University, Ile-Ife, Nigeria · 2: Department of Mental Health, State Specialist

Hospital, Osogbo, Nigeria

AUthors' CONTRibutions - A: Study design - B: Data collection - C: Statistical analysis - D: Data interpretation .

E: Manuscript preparation · F: Literature search · G: Funds collection

CORRESPONDing AUthor - Olutayo Aloba, FWACPsych, Obafemi Awolowo University, Department of Mental Health,

Faculty of Clinical S, 1231, Ile-Ife, Nigeria, e-mail: alobatee2002@gmail.com

to CITE THIS ARTICLE - Aloba, O., Opakunle, T., \& Ogunrinu, O. (2019). Psychometric characteristics and measurement

invariance across genders of the Multidimensional Scale of Perceived Social Support (MSPSS) among Nigerian

adolescents. Health Psychology Report, 7(1), 69-80. https://doi.org/10.5114/hpr.2019.82629

RECEIVED 08.08.2018 · REVIEWED 25.12.2018 · ACCEPTED 27.12.2018 · PUBLISHED 30.01.2019 


\section{BACKGROUND}

Perceived social support has been reported to act as a cushion for psychological distress, the deficiency of which may precipitate unfavorable consequences such as poor physical and mental health among adolescents (Klineberg et al., 2006). Studies have indicated significant positive correlations between perceived social support and satisfactory adjustment and academic performance (Decker, Dona, \& Christenson, 2007). Among adolescents, deficits
Olutayo Aloba, Tolulope Opakunle, Olakunle Ogunrinu in perceived social support from family members have been reported to prospectively correlate with depressive symptoms (Khatib, Bhui, \& Stansfeld, 2013). A multinational study which examined the association between social support and mental wellbeing among adolescents reported that increased perception of social support from a caring family member or significant others negatively correlated with the severity of depressive symptoms (Cheng et al., 2014). Apart from the adolescent population, the importance and influence of social support have been described among diverse populations such as caregivers of patients with oncological disorders (Dębska, Pasek, \& Wojtyna, 2017), individuals with sudden loss of auditory function (Hricová, 2018), patients receiving treatment for rheumatoid arthritis (Akintayo et al., 2018) and nursing students (Zarzycka, Ślusarska, Dyk, Bednarek, \& Trojanowska, 2018).

Among adolescents, reduced perceived social support from family and close friends statistically predicted a higher frequency of suicidal ideations and an increased number of suicide attempts (Miller, Esposito-Smythers, \& Leichtweis, 2015). In a crosssectional sample of American adolescent college students, higher levels of perceived social support had a protective effect against suicidal behaviors through the promotion of self-efficacy (Thompson, Eggert, \& Herting, 2000). Satisfactory perceived social support from parents and close friends has also been reported to have a buffering effect regarding the association between depression and suicidal ideation among male and female adolescents (Fredrick, Demaray, Malecki, \& Dorio, 2018). Also, a number of researchers of the adolescent population have reported significant positive relationships between social support and self-esteem (Marshall, Parker, Ciarrochi, \& Heaven, 2014).

Zimet and colleagues originally created the Multidimensional Scale of Perceived Social Support (MSPSS) to qualitatively measure three categories of subjectively perceived social support, 1) Family, 2) Friends and, 3) Significant others, among university undergraduate students (Zimet, Dahlem, Zimet, \& Farley, 1988). Each item of the three sources of support is worded in a manner that evaluates the availability (e.g., item 9 on the Friends subscale: I have friends with whom I can share my joys and sorrows) or the purpose of the support (e.g., item 12 on the Friends subscale: I can talk about my problems with my friends). Originally, the scale consisted of 24 items scored on a 5-point Likert scale. It was subsequently shortened to 12 items following item content and exploratory data analyses in a sample of undergraduate students (Zimet et al., 1988). Each of the 3 subscales (Family, Significant others and Friends) in the 12-item version consists of 4 items scored on a 7-point Likert scale from 1 (very strongly disagree) to 7 (very strongly agree). The respondent's indications for each item are summed up to obtain a composite score (i.e., overall perceived social support).

In developed countries, the MSPSS has been repeatedly shown to conform to the original 3-dimensional construct, with each subscale having satisfactory reliability in non-clinical samples of adolescent and young adult populations (CantyMitchell \& Zimet, 2000; Guan, Seng, Hway Ann, \& Hui, 2015; Guan et al., 2013; Ng, Amer Siddiq, Aida, Zainal, \& Koh, 2010). However, some researchers have reported models different from the original one. Issues with the factor structure were initially raised by Stanley et al., who reported that the scale exhibited a bi-dimensional structure in a sample of older adults on treatment for generalized anxiety disorder (Stanley, Beck, \& Zebb, 1998). However, they stated that they could not conclusively confirm this 2-factor model due to their small sample size $(N=50)$ (Stanley et al., 1998). In the model described by Stanley et al., the items of the Family and Significant others subscales merged into a single factor. Another study (Chou, 2000) which examined the factor structure in a sample of 475 Chinese adolescents also reported a 2 -factor model, but in contrast to the model described among the elderly patients with generalized anxiety disorder (Stanley et al., 1998), the items of the Friends and Significant others subscales constituted a single factor. Authors from Hong Kong also replicated this 2-factor model (Friends and Significant others constituting a single factor) in a sample of 2105 high school adolescents (Cheng \& Chan, 2004). In addition, a study that involved a student sample $(N=549)$ and a clinical sample of patients with depressive disorders $(N=156)$ yielded the best model fit indices with a higherorder 3-factor structure in both samples (Clara, Cox, Enns, Murray, \& Torgrudc, 2003).

An electronic literature search revealed two studies that have examined the factor structure, validity and reliability of the scale among adult stroke survivors in Northern Nigeria (Hamza \& Mohsein, 2012; Mohammad, Al Sadat, Loh, \& Chinna, 2015). The best model fit indices were obtained with the 2 -factor model in which the Family and Significant others subscales items merged as a single fac- 
tor (Mohammad et al., 2015). To the knowledge of the authors of this current study, the psychometric characteristics of the MSPSS in terms of its factor structure, reliability and validity among the Nigerian adolescent population have not been examined.

The establishment of measurement invariance is a prerequisite for the valid comparison of the responses to the items of a scale across different groups (Vandenberg \& Lance, 2000). Due to the frequent differences in the perceived social support reported between the male and female genders (Canty-Mitchell \& Zimet, 2000), it is important to examine measurement invariance in order to evaluate whether the items and subscales of the MSPSS have equivalent meanings for both the male and female Nigerian adolescents.

The purpose of this current study was to examine the factor structure, reliability, validity, and gender measurement invariance of the MSPSS, which is an extensively utilized subjectively completed instrument that quantifies an individual's perception of his or her social support in a sample of senior high school Nigerian adolescents. We conducted confirmatory factor analysis (CFA) to examine the model fit indices of the four models of the MSPSS that have been reported in the literature (three first-order and one second-order factor models). The model that exhibited the best fit indices was used to evaluate measurement invariance across the two genders by performing a series of nested multi-group CFA.

\section{PARTICIPANTS AND PROCEDURE}

\section{PARTICIPANTS}

The study sample consisted of senior high school adolescents attending the four government-owned secondary schools in Osogbo, a large city in Osun State, Southwestern Nigeria. The participants were selected using a multistage stratified sampling method. The first step was to randomly select four classrooms from each of the 3 arms of the senior secondary classes (I, II and III) in each high school, producing a total of 12 classrooms per school and an aggregate of 48 classrooms from all the four schools. The second step involved selecting 30 students from each classroom through balloting. Thus, a total of 1440 participants were recruited from all the four senior high schools. The Research and Ethics Committee of the Ladoke Akintola University of Technology Teaching Hospital (LTH), Osogbo, approved the research protocol. Approval was also obtained from the relevant regional educational authorities. The criteria for exclusion were students older than 19 years, those with a current or past history of having a mental disorder, those who refused to give their assent and those whose parents or guard- ians refused to give their consent. The students who assented gave their parents or guardians a consent form that explained the nature and purpose of the study. This consent form was to be signed by their parents or guardians, indicating their approval for the inclusion of their child in the study. Only those who returned the MSPSS and other study measures without any missing items were included in the final analysis. Five of the participants failed to complete either the MSPSS or one of the other study measures, leaving 1335 questionnaires for the final analysis.

\section{DATA COLLECTION MEASUREMENTS}

\section{Multidimensional Scale of Perceived Social Support (MSPSS)}

The MSPSS quantitatively evaluates an individual's perception of the social support obtained from three principal avenues, namely: Family (FAM), consisting of items 3, 4, 8, and 11; Friends (FRI), consisting of items 6, 7, 9, and 12; and Significant Others (SOs), consisting of items 1, 2, 5, and 10 (Zimet et al., 1988). The scale is a subjectively completed brief instrument consisting of a total of 12 items rated on a 7-point Likert scale. The total score ranges from 12 to 84 , with higher scores reflective of greater perceived social support. Four models of the MSPSS have been described in the literature; the original first-order 3-factor model (Zimet et al., 1988), two first-order 2-factor models (Chou, 2000; Stanley et al., 1998) and a second-order 3-factor model (Clara et al., 2003).

\section{Hospital Anxiety and Depression Scale (HADS)}

Anxiety and depressive symptoms among the adolescents were evaluated with the 14-item HADS. It has 2 subscales (anxiety and depression subscales), each consisting of 7 items (Zigmond \& Snaith, 1983). Each item is rated on a 4-point Likert scale ( 0 to 3 ). The cumulative scores on the anxiety and depressive subscales range from 0 to 21, with higher scores indicating more severe anxiety and depressive symptoms. Satisfactory psychometric characteristics of the HADS as a screening instrument for anxiety and depressive disorders have been demonstrated among the Nigerian non-clinical and clinical populations (Abiodun, 1994).

\section{Rosenberg's Self-Esteem Scale (RSES)}

The RSES has 10 items scored on a 4-point Likert (0 to 3 ) scale ranging from strongly agree to strongly disagree. Five of the scale's items are reversely coded (strongly disagree to strongly agree). The higher the
Social support among Nigerian adolescents 
aggregate score, the greater the respondent's perspective of their self-esteem (Rosenberg, 1965). Satisfactory validity and reliability have been described among Nigerian adolescents (Oyefeso \& Zacheaus, 1990).

\section{Positive and Negative Suicide Ideation (PANSI) Inventory}

The PANSI is a 14-item self-completed inventory consisting of 2 subscales: the Negative Suicide Ideation (PANSI-NSI) and the Positive Ideation (PANSI-PI) subscales. The PANSI-NSI consists of 8 items that evaluate the risk factors for suicidal behavior, while the PANSI-PI has 6 items which assess the factors that are considered to be protective against suicidal behavior (Osman, Gutierrez, Kopper, Barrios, \& Chiros, 1998). Each of the items on the PANSI-NSI and PANSI-PI is scored on a 5-point Likert scale ranging from 1 (none of the time) to 5 (most of the time). The aggregate scores on the PANSI-NSI and PANSI-PI range from 8 to 40 and 6 to 30 respectively. The lower and higher the aggregate scores on the PANSI-PI and PANSI-NSI, respectively, the greater is the risk of suicidal behavior. The scale is completed with the respondent putting into perspective the preceding 2 weeks. The utility of the PANSI as a suicide risk screening instrument was recently described among Nigerian adolescents and young adults (Aloba, Adefemi, \& Aloba, 2018).

\section{DATA ANALYSIS}

The analysis was performed with the $21^{\text {st }}$ version of the Statistical Package for Social Scientists (SPSS) and $\mathrm{R}$ psych package (version 3.4.2). Descriptive statistics such as frequency (percentage) and means (standard deviations) were used to depict the respondents' gender distribution and their scores on the MSPSS and other study measures. CFA was performed to evaluate 4 a priori models described in the literature with the $20^{\text {th }}$ version of the SPSS Analysis of Moment Structure (AMOS) software using the Maximum Likelihood Estimation (MLE) with covariance matrix input method. CFA is a technique in structural equation modeling that evaluates whether a specified factor structure is compatible with the covariance of a group of manifest variables (Jacob et al., 1998). For each model, the following fit indices were used for assessment: the significance of the ratio of the chi-square $\left(\chi^{2}\right)$ and its associated degree of freedom $\left(\chi^{2} / d f\right)$, the comparative fit index (CFI) (Bentler, 1990), the root mean square error of approximation (RMSEA) (Steiger, 1990), and the standardized root mean square residual (SRMR). One limitation of the $\chi^{2} / d f$ ratio is its sensitivity to sample size, which invariably nearly always yields a significant $p$-value when the study samples are large, thereby wrongfully rejecting the model (Bentler \& Bonett, 1980; Jöreskog, 1993); therefore we focused on the CFI, RMSEA and SRMR values. A CFI value greater than 0.90 reflects an acceptable fit, although values of 0.95 and above are considered excellent (Marsh, Hau, \& Wen, 2004). A CFI value of 0.90 is a generally accepted cut-off that indicates satisfactory data fit to the model (Van Lieshout, Cleverley, Jenkins, \& Georgiades, 2011). RMSEA and SRMR values between 0.06 and 0.08 indicate an acceptable model fit while values below 0.06 support an excellent model fit (Brown, 2006; Hu \& Bentler, 1999; Kline, 2005). The overall purpose was to determine which of the 4 models through CFA our data will fit the best.

Next, the criterion validity of the model with the best fit indices was examined via correlational analyses with the HADS-Anxiety and Depression subscales, the RSES and the Negative Suicide Ideation (NSI) and Positive Ideation (PI) subscales of the PANSI. We examined the model's internal consistencies (reliabilities) by calculating MacDonald's omega $(\omega)$ values in lieu of Cronbach's alpha $(\alpha)$, which has been reported to be a statistically flawed estimation of scale items' internal consistency (Crutzen \& Peters, 2017). The omega $(\omega)$ values yield a better estimate of the reliability of the aggregate score of the items within a construct (Brunner, Nagy, \& Wilhelm, 2012).

\section{Measurement invariance (MI)}

Afterward, we examined the gender equivalency of the model with the best fit indices. This step involves the examination of the changes in the model fit indices following the imposition of increasing invariance restrictiveness on the models (Byrne, 2013b). Serious attention is now given to factor model equivalency in the context of research involving different groups (Vandenberg \& Lance, 2000). An important statistical tool that has enabled comparison of group differences in relation to $\mathrm{MI}$ is multi-group CFA (Raykov, Marcoulides, \& Li, 2012). To be able to explore the similarities and differences in the same construct across different categories or groups, item factor loadings and intercepts must be equivalent (invariant) across the categories or groups that are being compared (Byrne, 2004).

\section{Tests of measurement invariance across genders}

1. Confirmatory factor analysis - We performed a CFA separately for the male and female adolescents with the model that had the best fit indices. A model that reasonably fits the data separately for the male and female adolescents is the first step towards the establishment of MI (Byrne, 2004). 
2. Configural invariance - This is the most basic level of MI, in which all the parameters of the selected MSPSS model will be freely estimated across the male and female respondents. In configural invariance, both genders must exhibit the loading of the same observed variables (MSPSS 12 items) on the same MSPSS constructs (subscales). These loadings must be significant and the subscales should have correlations less than 1 . This level of MI establishes that there is similarity of the MSPSS model across both genders, although it does not show whether there is actual equivalency of measurement in both genders (Byrne, 2004). The establishment of configural invariance is a prerequisite for the next step.

3. Metric invariance - This $=$ level of MI evaluates whether the factor loadings (MSPSS subscales) of the same observed variables (MSPSS items) are equivalent across both genders (Byrne, 2004). The establishment of this level of MI means that the male and female adolescents interpreted the 12 items of the MSPSS in the same manner. Metric invariance is a prerequisite for the comparison of correlates of factors across groups (Byrne, 2004). It is evaluated by placing equal restrictions on the factor loadings between the MSPSS items and subscales across genders (Vandenberg $\&$ Lance, 2000). There are cut-off scores that determine whether a decrease in the fit indices of the metric MI model compared to the configural MI model is significant or not (Chen, 2007).

4. Scalar invariance - This level of MI must be established before the means of constructs (i.e., MSPSS subscales) can be compared across groups (Byrne, 2004). Scalar MI confirmation indicates that both the male and female adolescents adopted a similar response format to the MSPSS items and subscales (Byrne, 2004). The fulfillment of scalar MI means that any differences in relation to the 12 items of the MSPSS are not a result of factors such as gender bias regarding the use of the MSPSS. Scalar MI is assessed by equivalently placing constraints on the factor loadings (as performed when evaluating metric MI) and the item intercepts across the groups (Vandenberg \& Lance, 2000). The criteria for scalar MI establishment based on the decrease in fit indices compared to the metric MI model have been proposed (Chen, 2007; Cheung \& Rensvold, 2002).

\section{Criteria for the establishment of gender measurement invariance}

The establishment of gender measurement invariance for the MSPSS was based on the changes in the CFI $(\triangle \mathrm{CFI})$, RMSEA ( $\triangle \mathrm{RMSEA})$ and SRMR ( $\triangle \mathrm{SRMR})$. Metric invariance is supported by $\triangle \mathrm{CFI} \leq-0.01$, $\triangle \mathrm{RMSEA} \leq 0.015$ and $\triangle \mathrm{SRMR} \leq 0.03$ in comparison to the configural model, while scalar invariance is supported by $\triangle \mathrm{CFI} \leq-0.01, \triangle \mathrm{RMSEA} \leq 0.015$ and $\triangle \mathrm{SRMR} \leq 0.01$ compared to the metric model (Chen, 2007). A $\triangle$ CFI between the metric and scalar invariance models greater than 0.01 supports the absence of measurement invariance (Cheung \& Rensvold, 2002). The confirmation of both metric and scalar invariances supports the equivalency of the MSPSS model for both genders.

\section{RESULTS \\ SOCIODEMOGRAPHIC AND STUDY MEASURE DESCRIPTIVE CHARACTERISTICS}

As seen in Table 1, the male respondents constituted $45.4 \%$ of a total of 1335 senior high school adolescents. The mean age was $15.15(S D=1.29)$ with a range of 13 to 18 years. Also shown in Table 1 are the mean scores on the MSPSS and its subscales in addition to those of the other study measures.

\section{CORRELATIONS BETWEEN MSPSS AND OTHER STUDY MEASURES}

Table 2 shows the directions and strengths of the correlations (Pearson product-moment) between the 3-factor MSPSS models and the other study measures. Positive correlations were observed with

\section{Table 1}

Sociodemographic and study measures characteristics $(N=1335)$

\begin{tabular}{lc}
\hline Variables & $\begin{array}{c}n(\%) / \text { Mean }(S D) \\
\text { [Range] }\end{array}$ \\
\hline $\begin{array}{l}\text { Gender } \\
\quad \text { Male }\end{array}$ & $606(45.40 \%)$ \\
$\quad$ Female & $729(54.60 \%)$ \\
Age & $15.15(1.29)[13-18]$ \\
Total MSPSS & $47.67(20.59)[5-20]$ \\
MSPSS-Family subscale & $16.64(7.88)[4-28]$ \\
MSPSS-Significant others & $16.21(7.93)[4-28]$ \\
subscale & $14.82(7.07)[4-28]$ \\
MSPSS-Friends subscales & $19.19(3.94)[0-30]$ \\
RSES & $8.27(3.96)[0-20]$ \\
HADS-Anxiety & $6.57(3.40)[0-19]$ \\
HADS-Depression & $12.13(5.47)[8-40]$ \\
PANSI-NSI & $17.74(6.35)[6-30]$ \\
PANSI-PI &
\end{tabular}

Social support among Nigerian adolescents 
the RSES and PANSI-PI subscales, while negative correlations were observed with PANSI-NSI and the HADS-Anxiety and depression subscales. There were good intercorrelations among the 3 MSPSS subscales $(r=.65-.92)$. Table 2 also shows the omega reliability values $\left(\omega_{\mathrm{h}}\right)$ of the 3 -factor MSPSS model and the other study measures.

\section{CONFIRMATORY FACTOR ANALYSIS}

Olutayo Aloba,

Tolulope Opakunle, Olakunle Ogunrinu

We examined the fit indices of our data for each of the four MSPSS models. Table 3 shows that the first (Zimet et al., 1988) and the fourth (Clara et al., 2003) models equivalently had the best fit indices with respect to the CFI and SRMR values. The CFA path diagrams and the item loadings of the first and second models are shown in Figure 1, while those of the third and fourth models are depicted in Figure 2.

\section{MEASUREMENT INVARIANCE IN RELATION TO GENDER}

Table 4 shows that among the males, the 3 -factor MSPSS model exhibited modestly acceptable fit indices in relation to the CFI (0.931) and SRMR (0.041) values. Among the male respondents, the item loadings on the Family subscale ranged from .73 to .83 , Significant others subscale item loadings ranged from .75 to .85 , while on the Friends subscale, item loadings ranged from .68 to .78 . Among the males, the correlations among the 3 subscales ranged from .80 to .95 . Among the females this model also exhibited modestly acceptable fit indices in relation to the CFI (0.949) and SRMR (0.039) values, with item loadings on the Family subscale ranging from .76 to .83 , Significant others subscale item loadings ranging from .73 to .81 , while on the Friends subscale item loadings ranged from .66 to .80 . Among the females, the correlations among the 3 factors ranged from 0.79 to 0.94 . Table 4 shows that the configural MI for the 3-factor MSPSS model had acceptable fit indices [CFI $=0.940$, RMSEA $=0.065(90 \% \mathrm{CI}$ : 0.060-0.069), SRMR $=0.049$ ]. Subsequently, a metric $\mathrm{MI}$ in relation to the genders also exhibited acceptable fit indices [CFI $=0.940$, RMSEA $=0.061(90 \%$ CI: 0.056-0.065), SRMR $=0.049]$. Likewise, a scalar MI after imposition of item intercept equality for both genders yielded acceptable model fit indices $[\mathrm{CFI}=0.941$, RMSEA $=0.058$ (90\% CI: 0.054-0.062), SRMR $=0.049]$. The changes in the CFI, SRMR and RMSEA values between the metric and scalar models were all acceptable for the establishment of gender measurement invariance for the 3-factor MSPSS models.

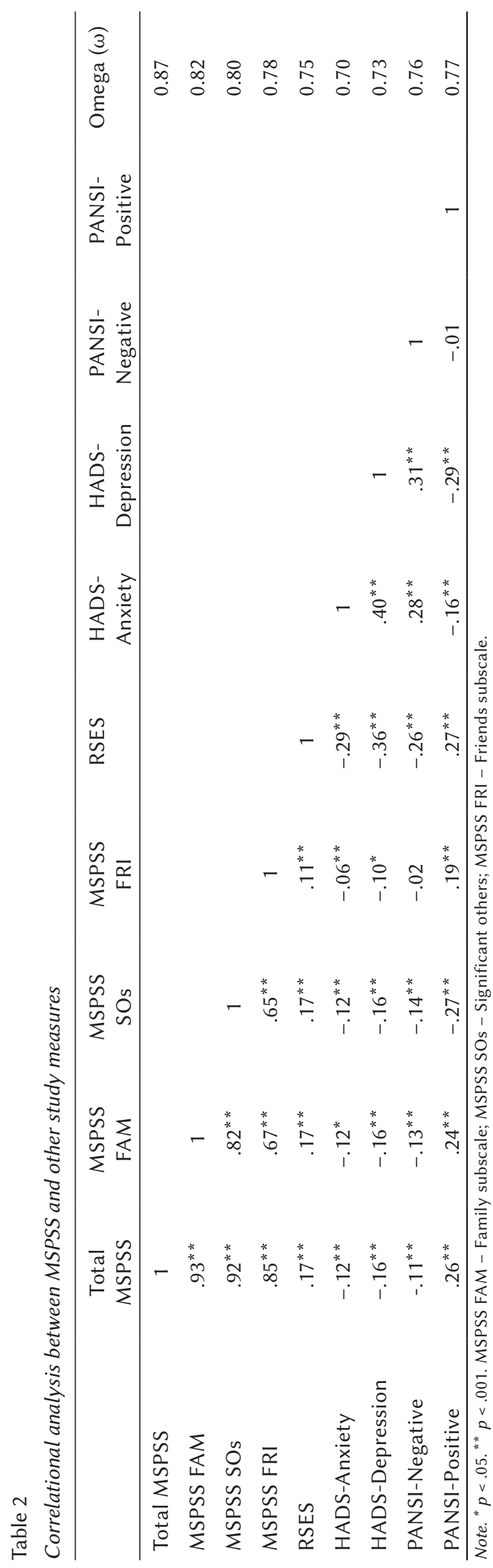


Table 3

Fit indices of the 4 MSPSS models among Nigerian adolescents

\begin{tabular}{lcccccc}
\hline MSPSS Models & $\chi^{2}$ & $d f$ & $\chi^{2} / d f$ & CFI & $\begin{array}{c}\text { RMSEA } \\
\text { [90\% confidence interval] }\end{array}$ & SRMR \\
\hline First-order & & & & & & \\
$\quad$ 3 factors (first model) & 556.48 & 51 & 10.91 & 0.946 & $0.086[0.080-0.093]$ & 0.041 \\
2 factors (second model) & 332.62 & 53 & 6.28 & 0.941 & $0.088[0.082-0.095]$ & 0.042 \\
2 factors (third model) & 936.91 & 53 & 17.68 & 0.906 & $0.112[0.105-0.118]$ & 0.055 \\
Second-order & & & & & & $0.086[0.080-0.093]$ \\
$\quad 3$ factors (fourth model) & 556.48 & 51 & 10.91 & 0.946 & 0.041 \\
\hline
\end{tabular}

Social support among Nigerian adolescents

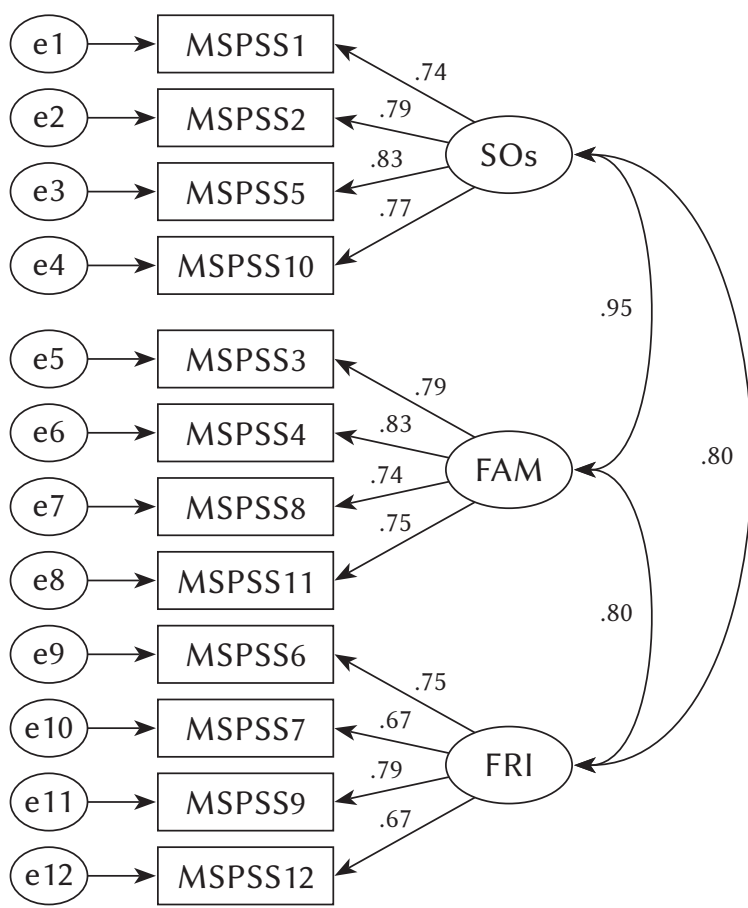

First-order three factor MSPSS model among Nigerian adolescents First model (Zimet, Dahlem, Zimet, \& Farley, 1988)

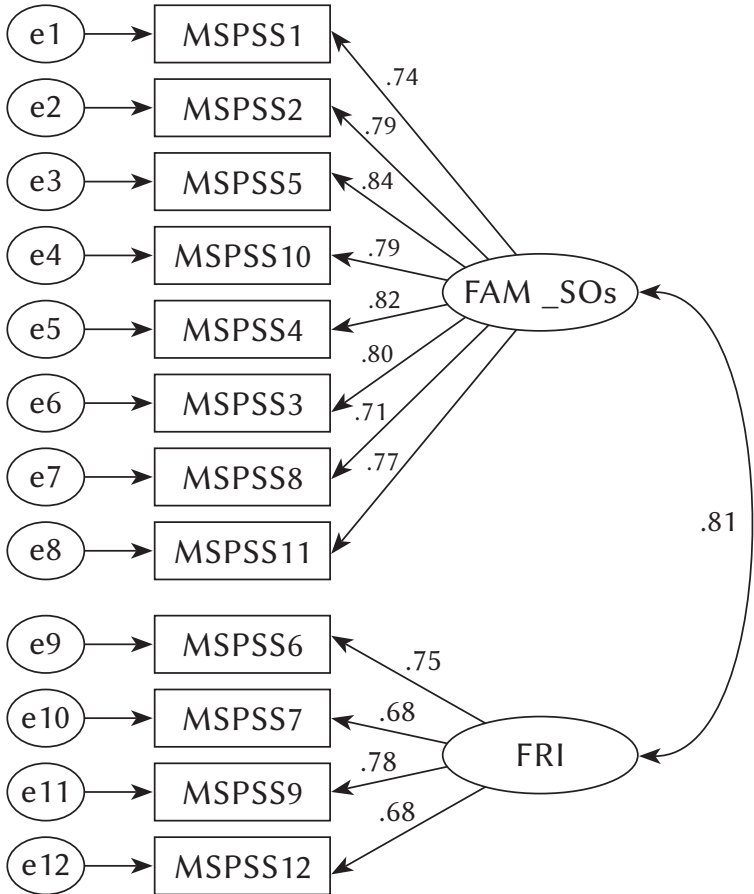

Second-order two factor MSPSS model among Nigerian adolescents

Second model (Stanley, Beck, \& Zebb, 1998)

Figure 1. Confirmatory factor analysis path diagrams depicting the first and second models of the MSPSS among the Nigerian adolescents SOs - Significant others; FAM - Family; FRI - Friends.

\section{DISCUSSION}

The main objective of this study is to examine the psychometric characteristics of the 12-item MSPSS in terms of its factor structure, internal consistency, and criterion validity, and in addition, to assess its measurement invariance (MI) across genders in a cross-sectional non-clinical sample of Nigerian senior high school adolescents $(N=1335)$. Four models of the MSPSS have been reported in the literature
(Chou, 2000; Clara et al., 2003; Stanley et al., 1998; Zimet et al., 1988). We examined which of these four models would exhibit the best fit indices with confirmatory factor analysis. Our study has yielded evidence in support of satisfactory psychometric properties and measurement invariance of the MSPSS in relation to gender among Nigerian adolescents.

Our results showed that our data equivalently exhibited the best fit to the first (Zimet et al., 1988) and the fourth MSPSS models (Clara et al., 2003). The fit indices of these two models were acceptable 
Olutayo Aloba,

Tolulope

Opakunle,

Olakunle

Ogunrinu
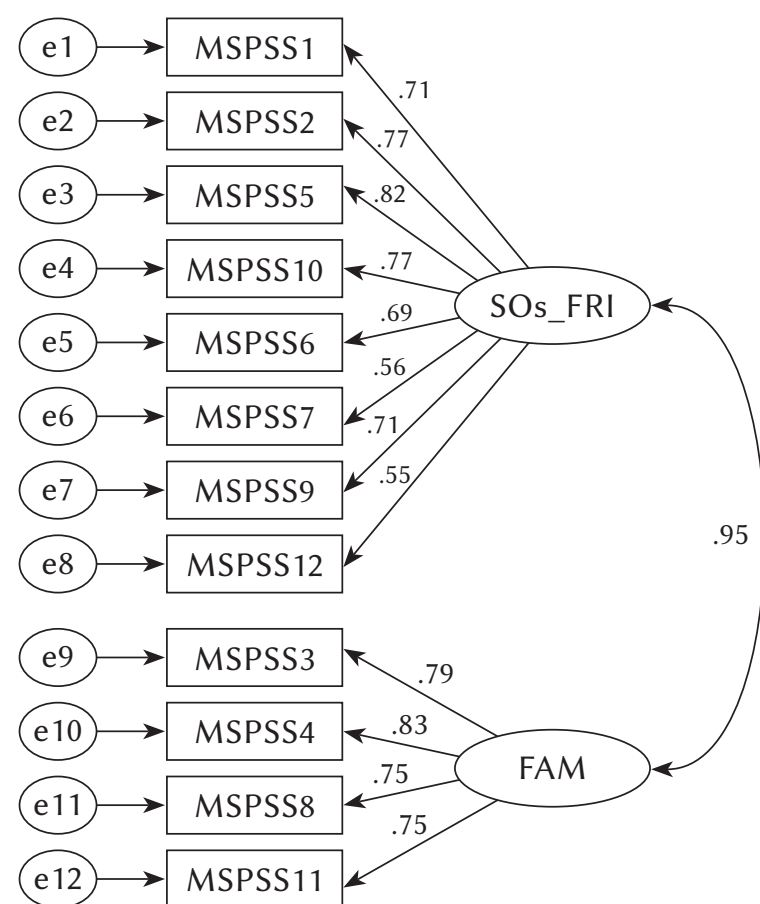

First-order two factor MSPSS model among

Nigerian adolescents

Third model (Chou, 2000)

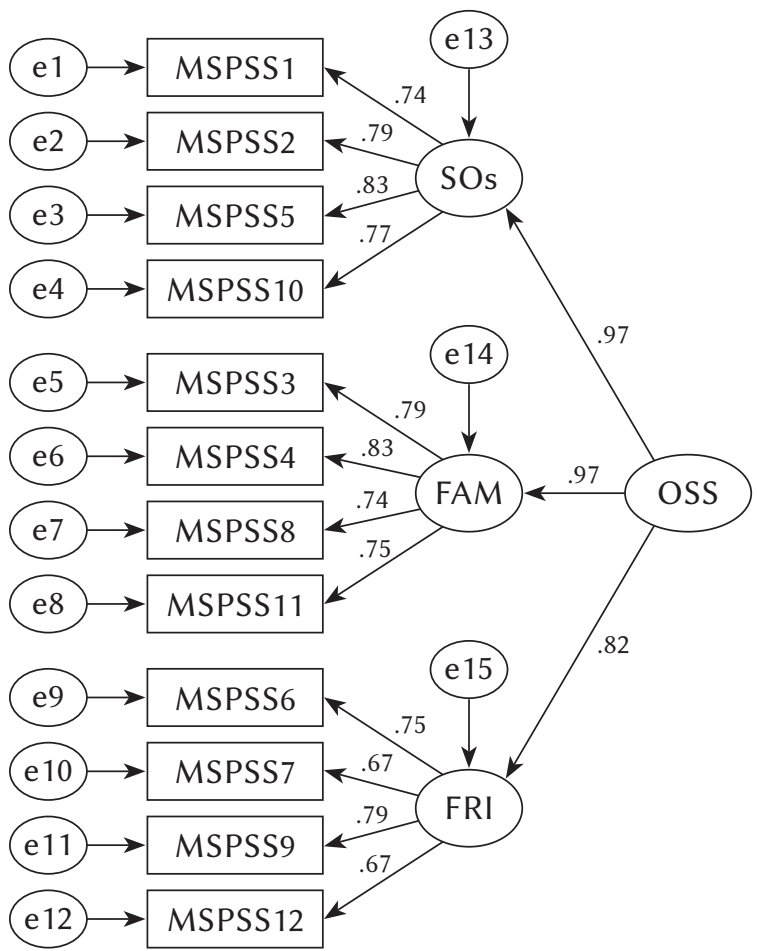

Second-order three factor MSPSS model among Nigerian adolescents

Fourth model (Clara, Cox, Enns, Murray, \& Torgrude, 2003)

Figure 2. Confirmatory factor analysis path diagrams depicting the third and fourth models of the MSPSS among the Nigerian adolescents SOs - Significant others; FAM - Family; FRI - Friends; OSS - Overall social support

Table 4

Test of gender invariance for the 3-factor MSPSS (first and fourth models)

\begin{tabular}{|c|c|c|c|c|c|c|c|c|}
\hline & $\begin{array}{l}\chi^{2} \\
(d f)\end{array}$ & $\chi^{2} / d f$ & CFI & $\triangle \mathrm{CFI}$ & SRMR & $\triangle \mathrm{SRMR}$ & $\begin{array}{l}\text { RMSEA } \\
90 \% \mathrm{CI}\end{array}$ & $\triangle \mathrm{RMSEA}$ \\
\hline \multicolumn{9}{|l|}{ Gender group CFA } \\
\hline Male & $\begin{array}{l}370.13 \\
(51)\end{array}$ & 7.26 & 0.931 & - & 0.041 & - & $\begin{array}{c}0.087 \\
{[0.077-0.098]}\end{array}$ & - \\
\hline Female & $\begin{array}{c}301.13 \\
(51)\end{array}$ & 5.91 & 0.949 & - & 0.039 & - & $\begin{array}{c}0.082 \\
{[0.073-0.091]}\end{array}$ & - \\
\hline \multicolumn{9}{|l|}{ Invariance nested models } \\
\hline $\begin{array}{l}\text { Configural } \\
\text { (unconstrained model) }\end{array}$ & $\begin{array}{c}671.28 \\
(102)\end{array}$ & 6.58 & 0.940 & - & 0.049 & - & $\begin{array}{c}0.065 \\
{[0.060-0.069]}\end{array}$ & - \\
\hline $\begin{array}{l}\text { Metric } \\
\text { (equal factor loadings) }\end{array}$ & $\begin{array}{l}677.65 \\
(114)\end{array}$ & 5.94 & 0.940 & 0.000 & 0.049 & 0.001 & $\begin{array}{c}0.061 \\
{[0.056-0.065]}\end{array}$ & 0.004 \\
\hline $\begin{array}{l}\text { Scalar } \\
\text { (equal item intercepts) }\end{array}$ & $\begin{array}{c}687.13 \\
(126)\end{array}$ & 5.45 & 0.941 & 0.001 & 0.049 & 0.000 & $\begin{array}{c}0.058 \\
{[0.054-0.062]}\end{array}$ & 0.003 \\
\hline
\end{tabular}


with respect to the CFI (0.946) and SRMR (0.041) values. The SRMR is the square root of the difference between the hypothesized covariance model and the sample covariance matrix residuals (Byrne, 2013a). Models with satisfactory fit indices have SRMR values less than 0.05 (Brown, 2006). The CFI values greater than 0.90 reflect that our data satisfactorily fitted the two 3-factor models of the MSPSS (Van Lieshout et al., 2011). As noted in Tables 3 (overall group CFA) and 4 (gender group CFA), the RMSEA values compared to the other indices were above the threshold for model acceptance. Instead of relying on a single parameter, it is recommended that researchers report several indices when examining the model fit (Kline, 2005). The recommendation is that the SRMR should be combined with other indices such as CFI or RMSEA (Hu \& Bentler, 1998; Kline, 2005). Different combinations of fit indices have been proposed for model rejection $(\mathrm{Hu}$ \& Bentler, 1998; Hu \& Bentler, 1999). A combination of CFI less than 0.95 and SRMR greater than 0.09 has been proposed for model rejection $(\mathrm{Hu}$ $\&$ Bentler, 1999). A model can also be rejected on the basis of a combination of RMSEA greater than 0.05 and SRMR greater than 0.06. Another combination that can be the basis for model rejection is RMSEA greater than 0.06 and SRMR greater than $0.09(\mathrm{Hu}$ $\&$ Bentler, 1999). Based on these fit indices combinations for model rejection, the first and fourth MSPSS models in this study are therefore acceptable.

Our CFA findings that showed better fit indices for the 3-factor models compared to the other models are consistent with previous observations among different non-clinical samples (Bruwer, Emsley, Kidd, Lochner, \& Seedat, 2008; Canty-Mitchell \& Zimet, 2000; Zimet, Powell, Farley, Werkman, \& Berkoff, 1990). In the first model (Zimet et al., 1988), the item loadings on each of the three factors were reasonably high (0.67-0.83). In addition, the 3 factors in the fourth model (Clara et al., 2003) had high loadings (0.82-0.97) on the overall perceived social support second-order domain among the $\mathrm{Ni}$ gerian adolescents. In the study that first described the fourth model, the three individual factors (Family, Significant others and Friends) exhibited moderate to high loadings (.63-.89) on the second-order global social support factor (Clara et al., 2003). It has been suggested that researchers involved with clinical and non-clinical samples can utilize either the individual three MSPSS factors or make use of the whole scale as a short instrument to evaluate the perception of overall social support (Clara et al., 2003; Vaingankar, Abdin, \& Chong, 2012). In our study, the second-order factor in the fourth model (OSS-overall social support) appears to be justified by the relatively high and similar factor loadings of the individual three first-order factors (Family, Significant others and Friends).
The 2-factor models (Chou, 2000; Stanley et al., 1998) compared to the 3-factor models had poorer fit indices. Our findings support the observation reported in a study of college students and psychiatric outpatients (Clara et al., 2003) in which the correlated 3-factor model (first model), as well as the second order model with a single domain of overall perceived social support (fourth model), exhibited a satisfactory fit. In contrast to our findings, a study that examined the factor structure of the MSPSS in a sample of patients $(N=140)$ receiving treatment for stroke in Northern Nigeria (Mohammad et al., 2015) reported that the first-order bifactor model (second model) initially reported among elderly patients with generalized anxiety disorder (Stanley et al., 1998) had the best model fit indices $(\mathrm{CFI}=0.955$, RMSEA $=0.079)$.

One initial step which will give methodological credence to the comparison of perceived social support between the Nigerian male and female adolescents will be the availability of a scale that exhibits measurement invariance (MI) across the genders. We performed multiple-group nested CFA to evaluate the configural, metric and scalar MI of the MSPSS in relation to the genders. According to the criteria for the establishment of MI (Chen, 2007; Cheung \& Rensvold, 2002), there were no significant decreases in the CFI along the three levels of MI for the first (Zimet et al., 1988) and fourth (Clara et al., 2003) MSPSS models. The changes in the RMSEA and SRMR along the three levels of MI were also not significant for either model. These observations support the usefulness of these two models in comparing the means of the constructs (Family, Significant others and Friends subscales) between the Nigerian male and female adolescents. The fulfillment of MI means that both the male and female adolescent subjects responded equivalently to the MSPSS in terms of its factor structure, its items, and subscales (Vandenberg \& Lance, 2000). Analysis of our data revealed that there were no significant differences between the male and female adolescents in relation to the items and subscales of the 3 factors of the MSPSS.

The internal consistency of the MSPSS and its subscales was examined by calculating the McDonald's omega $(\omega)$ values instead of Cronbach's alpha $(\alpha)$, which tends to inappropriately estimate the internal consistencies of multidimensional scales (Crutzen \& Peters, 2017). Another major advantage of McDonald's $\omega$ compared to Cronbach's $\alpha$ is that it takes into consideration the strength of the associations among the items and subscales of a multidimensional instrument in addition to the item-specific measurement errors (Crutzen \& Peters, 2017). To the knowledge of the authors, only one study (Osman, Lamis, Freedenthal, Gutierrez, \& McNaughton-Cassill, 2014) has applied McDonald's $\omega$ in the assess-
Social support among Nigerian adolescents 
Olutayo Aloba, Tolulope Opakunle, Olakunle Ogunrinu ment of the internal consistency of the MSPSS and its subscales. The interpretation of McDonald's $\omega$ is similar to Cronbach's $\alpha$, and as a general guideline, a value of 0.70 or above is indicative of the adequacy of a scale's internal consistency (Gliner, Morgan, \& Leech, 2011). Thus, the first and fourth models of the MSPSS equivalently exhibited satisfactory internal consistency among Nigerian adolescents.

The construct of perceived social support has been empirically associated with a number of psychological variables, such as reduced severity of depression and anxiety, and improved overall emotional and physical well-being (Vilchinsky et al., 2011). In our study, the directions and strengths of the correlations between the MSPSS and other measures were all as expected. There were significant modest negative correlations with anxiety and depressive symptoms and the vulnerability risk factors for suicidal behaviors. Significant modest positive correlations were observed with self-esteem and protective factors against suicidal behaviors. Therefore, we can conclude that the 3-factor MSPSS models have demonstrated to a modest extent satisfactory criterion validity.

Our study has a number of limitations. First, the adolescents in this study were from senior high schools in one of the six geopolitical zones (Southwestern Nigeria) of the country; therefore we are cautious in generalizing our findings to adolescents in the other zones. Second, a limitation of the measurement invariance analysis is that we did not examine the invariance of item unique variances; thus the items of the MSPSS may have unequal reliabilities across genders. Another limitation was that all the measures in our study were subjectively completed. Additional studies are needed to replicate our findings among other Nigerian populations such as clinical samples of adolescents. Researchers who are interested in evaluating perceived social support with the MSPSS among Nigerian adolescents can utilize either the first-order correlated 3-factor model (Zimet et al., 1988) or the second-order model (Clara et al., 2003).

\section{RefERENCES}

Abiodun, O. A. (1994). A validity study of the Hospital Anxiety and Depression Scale in general hospital units and a community sample in Nigeria. British Journal of Psychiatry, 165, 669-672.

Akintayo, R. O., Odunlami, G. J., Bamidele, O. F., Fabiyi, E. P., Akintayo, F. C., Bamidele, O. V., Dedeke, I. A., Osagie, T. T., \& Ibisola, A. A. (2018). The impacts of state and trait anxiety as moderated by perceived social support among Nigerian patients with rheumatoid arthritis. Reumatologia, 56, 155-163.
Aloba, O., Adefemi, S., \& Aloba, T. (2018). Positive and Negative Suicide Ideation (PANSI) Inventory: Initial Psychometric Properties as a Suicide Risk Screening Tool Among Nigerian University Students. Clinical Medicine Insights: Psychiatry, 9, 1-9.

Bentler, P. M. (1990). Comparative fit indexes in structural models. Psychological Bulletin, 107, 238-246.

Bentler, P. M., \& Bonett, D. G. (1980). Significance tests and goodness of fit in the analysis of covariance structures. Psychological Bulletin, 88, 588-606.

Brown, T. T. (2006). Confirmatory factor analysis for applied research. New York: Guilford Press.

Brunner, M., Nagy, G., \& Wilhelm, O. (2012). A tutorial on hierarchically structured constructs. Journal of Personality, 80, 796-846.

Bruwer, B., Emsley, R., Kidd, M., Lochner, C., \& Seedat, S. (2008). Psychometric properties of the Multidimensional Scale of Perceived Social Support in youth. Comprehensive Psychiatry, 49, 195-201.

Byrne, B. M. (2004). Testing for multigroup invariance using AMOS graphics: A road less traveled. Structural Equation Modeling, 11, 272-300.

Byrne, B. M. (2013a). Structural equation modeling with LISREL, PRELIS, and SIMPLIS: Basic concepts, applications, and programming. London: Psychology Press.

Byrne, B. M. (2013b). Structural equation modeling with Mplus: Basic concepts, applications, and programming. London: Routledge.

Canty-Mitchell, J., \& Zimet, G. D. (2000). Psychometric properties of the Multidimensional Scale of Perceived Social Support in urban adolescents. American Journal of Community Psychology, 28, 391-400.

Chen, F. F. (2007). Sensitivity of goodness of fit indexes to lack of measurement invariance. Structural Equation Modeling, 14, 464-504.

Cheng, S. T., \& Chan, A. C. (2004). The multidimensional scale of perceived social support: dimensionality and age and gender differences in adolescents. Personality and Individual Differences, 37, 1359-1369.

Cheng, Y., Li, X., Lou, C., Sonenstein, F. L., Kalamar, A., Jejeebhoy, S., Delany-Moretlwe, S., Brahmbhatt, H., Olumide, A. O., \& Ojengbede, O. (2014). The Association Between Social Support and Mental Health Among Vulnerable Adolescents in Five Cities: Findings From the Study of the Well-Being of Adolescents in Vulnerable Environments. Journal of Adolescent Health, 55, S31-S38.

Cheung, G. W., \& Rensvold, R. B. (2002). Evaluating goodness-of-fit indexes for testing measurement invariance. Structural Equation Modeling, 9, 233-255.

Chou, K. L. (2000). Assessing Chinese adolescents' social support: the multidimensional scale of perceived social support. Personality and Individual Differences, 28, 299-307.

Clara, I. P., Cox, B. J., Enns, M. W., Murray, L. T., \& Torgrudc, L. J. (2003). Confirmatory factor analysis of the multidimensional scale of perceived 
social support in clinically distressed and student samples. Journal of Personality Assessment, 81, 265-270.

Crutzen, R., \& Peters, G. Y. (2017). Scale quality: alpha is an inadequate estimate and factor-analytic evidence is needed first of all. Health Psychology Review, 11, 242-247.

Dębska, G., Pasek, M., \& Wojtyna, E. (2017). Does anybody support the supporters? Social support in the cancer patient-caregiver dyad. Family Medicine and Primary Care Review, 19, 110-113.

Decker, D. M., Dona, D. P., \& Christenson, S. L. (2007). Behaviorally at-risk African American students: The importance of student-teacher relationships for student outcomes. Journal of School Psychology, 45, 83-109.

Fredrick, S. S., Demaray, M. K., Malecki, C. K., \& Dorio, N. B. (2018). Can social support buffer the association between depression and suicidal ideation in adolescent boys and girls? Psychology in the Schools, 55, 490-505.

Gliner, J. A., Morgan, G. A., \& Leech, N. L. (2011). Research methods in applied settings: An integrated approach to design and analysis. London: Routledge.

Guan, N. C., Seng, L. H., Hway Ann, A. Y., \& Hui, K. O. (2015). Factorial validity and reliability of the Malaysian simplified Chinese version of the Multidimensional Scale of Perceived Social Support (MSPSS-SCV) among a group of university students. Asia-Pacific Journal of Public Health, 27, 225-231.

Guan, N. C., Sulaiman, A. R., Seng, L. H., Ann, A. Y., Wahab, S., \& Pillai, S. K. (2013). Factorial validity and reliability of the Tamil version of the multidimensional scale of perceived social support among a group of participants in university Malaya medical center, Malaysia. Indian Journal of Psychological Medicine, 35, 385-388.

Hamza, A., Mohsein, N. A., \& Yim, L. (2012). Measuring perceived social support in stroke survivors: linguistic validation of the multidimensional scale of Perceived social support (MSPSS) in Hausa ( $\mathrm{Ni}$ gerian) language. South African Journal of Occupational Therapy, 42, 26-29.

Hricová, M. (2018). Coping strategies and social environment of patients with sudden hearing loss. Health Psychology Report, 6, 216-221.

Hu, L., \& Bentler, P. M. (1998). Fit indices in covariance structure modeling: Sensitivity to underparameterized model misspecification. Psychological Methods, 3, 424-453.

Hu, L., \& Bentler, P. M. (1999). Cutoff criteria for fit indexes in covariance structure analysis: Conventional criteria versus new alternatives. Structural Equation Modeling, 6, 1-55.

Jacob, K., Everitt, B., Patel, V., Weich, S., Araya, R., \& Lewis, G. (1998). The comparison of latent vari- able models of non-psychotic psychiatric morbidity in four culturally diverse populations. Psychological Medicine, 28, 145-152.

Jöreskog, K. G. (1993). Testing structural equation models. Sage Focus Editions, 154, 294-294.

Khatib, Y., Bhui, K., \& Stansfeld, S. A. (2013). Does social support protect against depression \& psychological distress? Findings from the RELACHS study of East London adolescents. Journal of Adolescence, 36, 393-402.

Kline, R. B. (2005). Principles and Practice of Structural Equation Modeling (2nd ed.). New York: Guilford.

Klineberg, E., Clark, C., Bhui, K. S., Haines, M. M., Viner, R. M., Head, J., Woodley-Jones, D., \& Stansfeld, S. A. (2006). Social support, ethnicity and mental health in adolescents. Social Psychiatry and Psychiatric Epidemiology, 41, 755-760.

Marsh, H. W., Hau, K.-T., \& Wen, Z. (2004). In Search of Golden Rules: Comment on Hypothesis-Testing Approaches to Setting Cutoff Values for Fit Indexes and Dangers in Overgeneralizing Hu and Bentler's (1999) Findings. Structural Equation Modeling, 11, 320-341.

Marshall, S. L., Parker, P. D., Ciarrochi, J., \& Heaven, P. C. L. (2014). Is self-esteem a cause or consequence of social support? A 4-year longitudinal study. Child Development, 85, 1275-1291.

Miller, A. B., Esposito-Smythers, C., \& Leichtweis, R. N. (2015). Role of social support in adolescent suicidal ideation and suicide attempts. Journal of Adolescent Health, 56, 286-292.

Mohammad, A. H., Al Sadat, N., Loh, S. Y., \& Chinna, K. (2015). Validity and reliability of the Hausa version of the multidimensional scale of perceived social support index. Iranian Red Crescent Medical Journal, 17, 1-7.

Ng, C. G., Amer Siddiq, A. N., Aida, S. A., Zainal, N. Z., \& Koh, O. H. (2010). Validation of the Malay version of the Multidimensional Scale of Perceived Social Support (MSPSS-M) among a group of medical students in the Faculty of Medicine, University Malaya. Asian Journal of Psychiatry, 3, 3-6.

Osman, A., Gutierrez, P. M., Kopper, B. A., Barrios, F. X., \& Chiros, C. E. (1998). The positive and negative suicide ideation inventory: development and validation. Psychological Report, 82, 783-793.

Osman, A., Lamis, D. A., Freedenthal, S., Gutierrez, P. M., \& McNaughton-Cassill, M. (2014). The multidimensional scale of perceived social support: analyses of internal reliability, measurement invariance, and correlates across gender. Journal of Personality Assessment, 96, 103-112.

Oyefeso, A. O., \& Zacheaus, A. (1990). Self-esteem as Determined by Gender Differences among Yoruba Adolescents in Ibadan, Nigeria: A Research Note. Journal of Child Psychology and Psychiatry, 31, 461-463.

Raykov, T., Marcoulides, G. A., \& Li, C.-H. (2012). Measurement invariance for latent constructs in multiple
Social support among Nigerian adolescents 
Olutayo Aloba,

Tolulope Opakunle,

Olakunle Ogunrinu populations: A critical view and refocus. Educational and Psychological Measurement, 72, 954-974.

Rosenberg, M. (1965). Society and the adolescent selfimage (Vol. 11). Princeton, NJ: Princeton University Press.

Stanley, M. A., Beck, J. G., \& Zebb, B. J. (1998). Psychometric properties of the MSPSS in older adults. Aging \& Mental Health, 2, 186-193.

Steiger, J. H. (1990). Structural Model Evaluation and Modification: An Interval Estimation Approach. Multivariate Behavioral Research, 25, 173-180.

Thompson, E. A., Eggert, L. L., \& Herting, J. R. (2000). Mediating effects of an indicated prevention program for reducing youth depression and suicide risk behaviors. Suicide and Life-Threatening $\mathrm{Be}$ havior, 30, 252-271.

Vaingankar, J. A., Abdin, E., \& Chong, S. A. (2012). Exploratory and confirmatory factor analyses of the Multidimensional Scale of Perceived Social Support in patients with schizophrenia. Comprehensive Psychiatry, 53, 286-291.

Vandenberg, R. J., \& Lance, C. E. (2000). A review and synthesis of the measurement invariance literature: Suggestions, practices, and recommendations for organizational research. Organizational Research Methods, 3, 4-70.

Van Lieshout, R. J., Cleverley, K., Jenkins, J. M., \& Georgiades, K. (2011). Assessing the measurement invariance of the Center for Epidemiologic Studies Depression Scale across immigrant and non-immigrant women in the postpartum period. Archives of Women's Mental Health, 14, 413-423.

Vilchinsky, N., Dekel, R., Leibowitz, M., Reges, O., Khaskia, A., \& Mosseri, M. (2011). Dynamics of support perceptions among couples coping with cardiac illness: the effect on recovery outcomes. Health Psychology, 30, 411-419.

Zarzycka, D., Ślusarska, B., Dyk, D., Bednarek, A., \& Trojanowska, A. (2018). Polish adaptation of Interpersonal Support Evaluation List, a Version For Students (ISEL-48v.Coll: Interpersonal Support Evaluation List, College Version). Health Problems of Civilization, 11, 280-286.

Zigmond, A. S., \& Snaith, R. P. (1983). The Hospital Anxiety and Depression Scale. Acta Psychiatrica Scandinavica, 67, 361-370.

Zimet, G. D., Dahlem, N. W., Zimet, S. G., \& Farley, G. K. (1988). The multidimensional scale of perceived social support. Journal of Personality Assessment, 52, 30-41. 